\section{Neonatal hyperglycaemia after prolonged maternal treatment with diazoxide}

Diazoxide has been used to control severe hypertension in pregnancy. ${ }^{1}$ We report a case of severe neonatal hyperglycaemia after its prolonged use in a mother with hypertension.

\section{Case report}

A 25-year-old mother presented three years before her first pregnancy with a lupoid rash, arthralgia, acute hypertension, and renal failure: systemic lupus erythematosus was diagnosed. A test for antinuclear factor was positive, and DNA antibody binding was $92 \%$. She was treated with prednisolone and chlorambucil. Her hypertension was poorly controlled despite treatment with propranolol, methyldopa, hydralazine, and diazoxide, and on two occasions she had hypertensive convulsions. Over the next six months she improved so that antihypertensive treatment could be stopped. The systemic lupus erythematosus remained controlled with prednisolone $2.5 \mathrm{mg}$ daily, but autoimmune hypothyroidism was diagnosed and treated.

After conception blood pressure at 12 weeks of gestation was $140 / 90 \mathrm{~mm}$ $\mathrm{Hg}$ and she was excreting $3.8 \mathrm{~g}$ protein/24 hours. Antinuclear factor was present at a dilution of $1 / 20$, DNA antibody binding was $25 \%$, and serum C3 and $\mathrm{C} 4$ concentrations were normal.

At 28 weeks' gestation her blood pressure rose to $180 / 110 \mathrm{~mm} \mathrm{Hg}$ and methyldopa $250 \mathrm{mg}$ three times a day was started, which was rapidly increased to $750 \mathrm{mg}$ four times a day. Her blood pressure increased, however, to a maximum of $210 / 150 \mathrm{~mm} \mathrm{Hg}$, and so diazoxide $50 \mathrm{mg}$ given by mouth every eight hours was added, with some improvement. Urinary protein excretion varied from 0.3 to $2.6 \mathrm{~g} / 24$ hours. She remained asymptomatic. Clinically, the fetus was thought to be small for dates.

A live boy, birth weight $2090 \mathrm{~g}$ ( $<10$ th centile), was delivered at 36 weeks' gestation by elective caesarean section after 47 days of maternal treatment with diazoxide. During the first 72 hours after birth he developed mild hyaline membrane disease and required an increased inspired oxygen concentration. Orogastric feeds with human milk were stopped after 10 hours because of increasing tachypnoea, and an intravenous infusion of $5 \%$ dextrose was started at a rate of $2 \mathrm{mg}$ glucose $/ \mathrm{kg} / \mathrm{min}$. At 24 hours of age this was increased to $3.3 \mathrm{mg}$ glucose $/ \mathrm{kg} / \mathrm{min}$. By 55 hours of age his blood glucose concentration had risen to $16.9 \mathrm{mmol} / 1(304 \mathrm{mg} / 100 \mathrm{ml})$ with glycosuria but no ketonuria. Plasma insulin concentration at this time $(6.4 \mathrm{mU} / \mathrm{l})$ was inappropriately low, since in our laboratory concentrations less than $10 \mathrm{mU} / 1$ are normally associated with blood glucose concentrations less than $5 \mathrm{mmol} / \mathrm{l}$ (90 mg/100 ml). Actrapid (Novo) insulin was infused at a rate of 0.1 units/hour, and the blood glucose concentration returned to normal (figure).

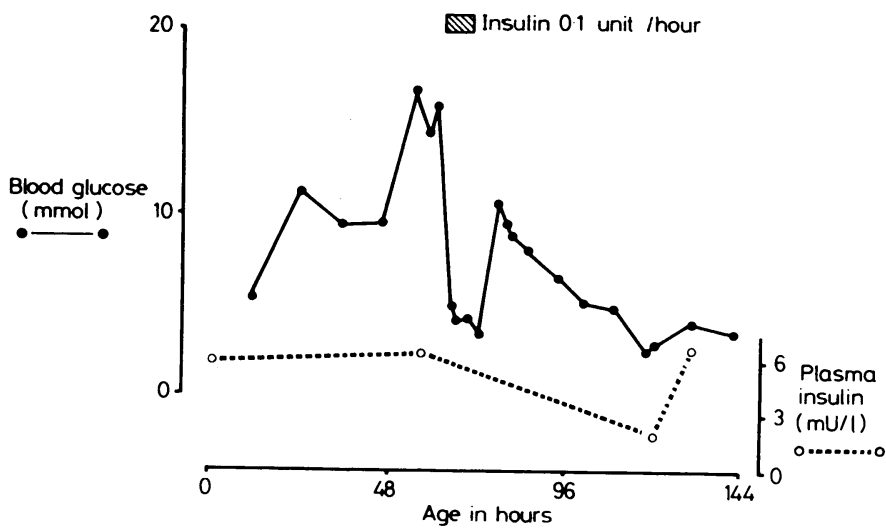

Blood glucose and plasma insulin concentrations in first six days of life.

Conversion: SI to traditional units-Glucose: $1 \mathrm{mmol} / 1 \approx 18 \mathrm{mg} / 100 \mathrm{ml}$.

The infusion rate of $5 \%$ dextrose was increased to compensate for an osmotic diuresis. The insulin was stopped after six hours; a small rebound rise in blood glucose concentration occurred, which then spontaneously returned to normal. Oral feeds with human milk were re-established. At 18 months of age he showed normal growth and development with no metabolic abnormality.

\section{Comment}

This is the first report of a neonate requiring treatment for hyperglycaemia after prolonged exposure to diazoxide in utero. Control of severe maternal hypertension is a clear indication for the use of antihypertensive drugs in pregnancy. ${ }^{1}$ Our patient had previously had a life-threatening episode of hypertension and during pregnancy developed further hypertension that was not controlled by methyldopa alone. Oral diazoxide was then used successfully to prolong the pregnancy by nearly seven weeks.

Studies in animals have shown that diazoxide readily crosses the placenta and may cause fetal hyperglycaemia. ${ }^{2}$ Transient mild hyperglycaemia has also been noted in the neonate after a bolus of diazoxide was given intravenously shortly before delivery. ${ }^{34}$ Long-term treatment with oral diazoxide has been reported during pregnancy in only four mothers, who received $200-800 \mathrm{mg}$ daily for 19 to 69 days. Neonatal hyperglycaemia did not develop, but two infants, both born to diabetic mothers, had impaired glucose tolerance associated with diminished insulin secretion. ${ }^{5}$ The mother in this study received only $150 \mathrm{mg}$ diazoxide/day for 47 days and did not develop glucose intolerance. Her infant became hyperglycaemic despite a low rate of glucose infusion. Since there was an inappropriately low plasma insulin concentration for the degree of hyperglycaemia we suggest that this is compatible with transplacental transfer of diazoxide causing inhibition of release of insulin from the neonatal pancreas. The long half life of diazoxide (about 20 hours in adults), is compatible with this conclusion, though there are no data concerning the half life of diazoxide in the neonate. No other adverse side effects were seen; in particular, the infant did not develop alopecia, ${ }^{5}$ as has been reported previously.

${ }^{1}$ Redman CWG. The use of antihypertensive drugs in hypertension in pregnancy. Clin Obstet Gynecol 1977;4:685-705.

2 Boulos BM, Davis LE, Almond CH, Jackson RL. Placental transfer of diazoxide and its hazardous effect on the newborn. $\mathcal{f}$ Clin Pharmacol $1971 ; 11: 206-10$

${ }^{3}$ Milsap RL, Auld PAM. Neonatal hyperglycemia following maternal diazoxide administration. $\mathcal{F} A M A 1980 ; 243: 144-5$.

4 Neuman J, Weiss B, Rabello Y, Cabal L, Freeman RK. Diazoxide for the acute control of severe hypertension complicating pregnancy-a pilot study. Obstet Gynecol 1979:53, suppl:50-5.

5 Milner RDG, Chouksey SK. Effects of foetal exposure to diazoxide in man. Arch Dis Child 1972;47:537-43.

(Accepted 2 February 1982)

University Departments of Paediatrics and Obstetrics, John Radcliffe Hospital, Oxford OX3 9DU

M J SMITH, MRCP, registrar (present address: Alder Hey Children's Hospital, Liverpool)

A AYNSLEY-GREEN, DPHIL, MRCP, university lecturer in paediatrics

C W G REDMAN, FRCP, university lecturer in obstetric medicine

MEDICINES APPROPRIATED TO THE BREAST AND LUNGS-The medicines appropriated to the breast and lungs, you shall find called all along by the name of [pectorals] that's the term Physicians give them, when you hear them talk of pectoral Syrups, pectoral rows, or pectoral Ointments. They are divers, some of which regard the part afflicted, others the matter afflicting. But although sometimes in ulcers of the lungs, we are forced to use binding medicines, to join the ulcer, yet are not these called pectorals, because binding medicines are extreme hurtful to the breast and lungs, both because they hinder one's fetching his breath, and also because they hinder the avoiding that flegm by which the breast is oppressed. Such medicines are called pectorals, which are of a lenifying nature. Besides, Those which make thin matter thicker are of two sorts, viz Some are mild and gentle, which may safely be administed, be the matter hot or cold which offendeth; others are very cold, which are used on you when the matter offending is sharp. But because such medicines as conduct to the cure of the phthisics (which is an ulceration of the lungs, and the disease usually called, the consumption of the lungs,) are also reckoned in amongst pectorals, it is not amiss to speak a word or two of them.

In the cure of this disease are three things to be regarded. 1. To cut and bring away the concreted blood. 2. To cherish and strengthen the lungs. 3. To conglutinate the ulcer. And indeed some particular simples will perform all these, and physicians confess it; which shews the wonderful mystery the all-wise God hath made in the creation, that one and the same simple should perform two contrary operations on the same part of the body; for the more a medicine cleanses, the more it conglutinates.

To conclude then, Pectoral Medicines are such as either cut and cleanse out the compacted humours from the arteries of the lungs, or make thin defluxions thick, or temper those that are sharp, help the roughness of the wind-pipe, or are generally lenitive and softening, being outwardly applied to the breast. (Nicholas Culpeper (1616-54) The Complete Herbal, 1850.) 